\section{Kidney Blood Pressure Research}

\title{
The Inhibitory Effect of Rapamycin on Toll Like Receptor 4 and Interleukin 17 in the Early Stage of Rat Diabetic Nephropathy
}

\author{
Ruichao Yu ${ }^{a, b}$ Hong Bo ${ }^{c}$ Vincenzo Villanid ${ }^{d}$ Philip J. Spencer ${ }^{d} \quad$ Ping Fu $^{a}$
}

aSichuan University, West China Hospital, Department of Nephrolog, Wuhou District, Chengdu, Sichuan, China; ${ }^{b}$ Center for Transplantation Sciences, Harvard Medical School, Massachusetts General Hospital, Boston, MA, USA; 'Sichuan University, West China Hospital, Department of Intensive Care Unit, Wuhou District, Chengdu, Sichuan, China; dDepartment of Surgery, Massachusetts General Hospital, Boston, MA, USA

\section{Key Words}

Diabetic nephropathy (DN) • Toll-like receptor 4 (TLR4) • Interleukin-17 (IL-17) • Rapamycin

\begin{abstract}
Background/Aims: There is increasing evidence showing that innate immune responses and inflammatory processes play an important role in the development and progression of diabetic nephropathy (DN). The potential effect of innate immunity in the early stage of DN is still unclear. Toll-Like-Receptor 4 (TLR4) is vigorously involved in the progress of kidney diseases in a sterile environment. The activation of the interleukin 17 (IL-17) pathway produces inflammatory cytokines, appearing in various kidney diseases. Unfortunately the relationship between TLR4 and IL-17 has not been investigated in diabetic nephropathy to date. The aim of this study is to investigate whether mammalian target of rapamycin (mTOR) inhibition may be dependent on TLR4 signaling and the pro-inflammatory factor IL-17 to delay the progression of DN. Methods: Streptozotocin (STZ)-induced diabetic rats were randomly assigned to 3 experimental groups: a diabetic nephropathy group ( $D N, n=6)$; and a diabetic nephropathy treated with rapamycin group (Rapa, $\mathrm{n}=6$ ) and a control group (Control, $\mathrm{n}=6$ ). Body weight, fasting blood sugar, and 24h urine albumin were assessed at week 2, week 4 and week 8. Renal tissues were harvested for H\&E, PAS staining, as well as an immunohistochemistry assay for TLR4 and IL-17. TLR4 quantitative expression was measured by Western-Blot analysis and RT-PCR. Results: Our results demonstrated that the expression of both TLR4 and IL-17 were upregulated in early stage DN and reduced by rapamycin. TLR4 and IL-17 both increased and positively related to $24 \mathrm{~h}$ urinary albumin and kidney/weight ratio. However, neither TLR4 nor IL-17 made a significant difference on fasting blood sugar. Conclusions: Taken together, our results confirm and extend previous studies identifying the significance of the TLR4 and Th17 pathways in development of early stage DN. Furthermore, we suggest this overexpression of




\section{Kidney Blood Pressure Research}

Yu/Bo/Villani/Spencer/Fu: The Effect of Rapamycin on TLR-4 and IL-17 in DN

TLR4 might be involved in the immunopathogenesis of DN through activation of Th17 cells. Rapamycin may attenuate DN via reduction of the TLR4 signaling pathway and Th17 cells signaling. Although the underlying mechanisms need to be explored, the observed increase of TLR4 and IL-17 during the early stages of DN and their suppression with rapamycin treatment suggest the importance of TLR4 and IL-17 in DN pathophysiology.

\section{Introduction}

Diabetic nephropathy (DN) is one of the most common causes of end-stage kidney disease (ESKD). Twenty to $40 \%$ of diabetic patients develop stage 5 chronic kidney disease [1]. It is well known that diabetic nephropathy can be attributed to multiple factors, including genetic mutation, hyperglycemia, and hemodynamic changes [2]. Even though DN is generally considered to be a non-inflammatory disease, there is increasing evidence that the innate immune response and inflammatory processes play a major role in the development and progression of DN $[3,4]$. Inflammation is considered to be crucial to the pathogenesis of diabetic nephropathy $[5,6]$. In addition to increased macrophage infiltration and overproliferation of leucocyte adhesion molecules [7, 8], kidney proximaltubular cells can release cytokines, chemoattractants, and matrix proteins into the interstitium when stimulated, accelerating the inflammatory process [9-11]. The etiopathology of DN is still not completely understood to date, and more effective forms of therapy are needed.

Toll-like receptor-4 (TLR4) is vigorously involved in the progression of kidney diseases in a sterile environment. This molecule recruits both the MyD88-dependent and MyD88independent pathways during TLR4-mediated proliferation of inflammatory cytokines [12]. TLR4 expression is upregulated on tubular endothelial cells (TECs) and podocytes in glomerular injury, and TLR4-induced inflammation can possibly mediate the progression of DN $[13,14]$. Recent experimental studies suggested that knocking out TLR4 attenuates renal inflammation, fibrosis, and podocytopathy [15]. Previous studies have shown that in T1DM patients there is an increased expression and activity of TLR4 on monocytes, which appears to be further accentuated in DN patients [16]. Furthermore, they have shown that genetic deficiency of TLR4 reduces systemic and macrophage inflammation in T1DM [17].

Interleukin-17(IL-17) is a pro-inflammatory factor that is produced by a number of cells, including T helper 17 (Th17) cells, CD8+ T cells, and NK cells. IL-17 acts as a proinflammatory cytokine, recruiting neutrophils and monocytes to the inflammatory site. This process induces production of downstream cytokines including IL-1 $\beta$, IL-6, transforming growth factor (TGF)- $\beta$, tumor necrosis factor (TNF)- $\alpha$, and interferon (IFN)- $\gamma$ [18]. A recent study demonstrated that the development of end stage kidney disease was affected by the polymorphisms of IL-17E and IL-17RA genes [19]. The activation of the IL-17 pathway produces inflammatory cytokines appearing in various kidney diseases, such as kidney ischemia-reperfusion injury (IRI) [20], lupus nephritis (LN) [21], and acute renal obstruction [22]. However, the influence of IL-17 expression on diabetic nephropathy is still not completely clear.

Mammalian target of rapamycin (mTOR) is a serine/threonine protein kinase that regulates cell growth, cell proliferation, cell motility, cell survival, protein synthesis, autophagy, and transcription. mTOR belongs to the phosphatidylinositol 3-kinase (PI3k)related kinase protein family. mTOR integrates the input from upstream pathways, including insulin, growth factors, and amino acids [23]. Alterations in the mTOR pathway have been reported in several human diseases, such as diabetes, obesity, and certain types of malignancy [24]. Rapamycin inhibits mTOR by associating with its intracellular receptor, FK506-binding protein 12 (FKBP12). The FKBP12-rapamycin complex binds directly to the FKBP12- 


\section{Kidney \\ Blood Pressure Research}

Kidney Blood Press Res 2016;41:55-69

\begin{tabular}{l|l}
\hline DOI: 10.1159/000368547 & (C) 2016 The Author(s). Published by S. Karger AG, Base
\end{tabular}

Published online: February 07, 2016 www.karger.com/kbr

Rapamycin Binding (FRB) domain of mTOR, inhibiting its activity [25]. The activation of mTOR has been shown to enhance TLR4 signaling by formation of the mTOR Complex 2, a protein complex that regulates the cellular metabolism through Akt/PKB (protein kinase B) [26]. However, the mechanism of mTOR signaling in DN is still unclear.

The purpose of this study was to test the potential effect of innate immunity in the early stage of DN. Specifically, we tested whether mTOR inhibition rapamycin was dependent on TLR4 signaling in order to stimulate pro-inflammatory factor IL-17 and demonstrate renal protection against diabetic nephropathy.

TLR ligands are known to play a role in the development of chronic inflammatory reactions, especially those containing a robust Th17 component [27]. Accordingly, high expression of inflammatory mediators as Myd88, interleukin-1 receptor-associated kinase 4 (IRAK4), and nuclear factor $\kappa \mathrm{B}(\mathrm{NF}-\kappa \mathrm{B})$ are reported to release high levels of IL-1, IL6, IL-8 and IL-17 [28]. NF- $\kappa B$ is stimulated in response to TLR4 production in the highglucose environment of the proximal tubular cells [29]. Upon activation, NF- $\kappa B$ regulates the expression of a great number of cell adhesion molecule proteins, chemokines and proinflammatory cytokines, including IL-17. Unfortunately the relationship between TLR4 and IL-17 has not been investigated in diabetic nephropathy to date. We hypothesized that mTOR inhibitory may be dependent on TLR4 signaling and the pro-inflammatory factor IL-17 to delay the progression of DN.

\section{Materials and Methods}

Animals

Fifty-four 8-week old specific pathogen-free male Sprague-Dawley (SD) rats were purchased from the State Key Laboratory of the Sichuan University (Chengdu, China). Animals (220-260g) were housed in temperature controlled rooms $\left(20-22^{\circ} \mathrm{C}\right)$ with constant humidity (40-70\%) as well as 12/h light and $12 / \mathrm{h}$ dark cycles for one week. Rats were provided free access to water and to standard rodent chow.

All animal experiments were performed with the approval of the Animal Ethics Committee of the Sichuan University.

\section{Induction of diabetes}

Rats were randomly divided into 3 groups: a normal control group (Control, $\mathrm{n}=6$ ); a diabetic nephropathy group (DN, $n=6)$; and a diabetic nephropathy rapamycin treated (Rapa, $n=6)$. After one week of acclimation, the DN and Rapa rats were fasted for 12 hours then injected intraperitoneally with $55 \mathrm{mg} / \mathrm{kg}$ streptozocin (STZ) [30]. Seventy-two hours after STZ injection, the rats with a blood glucose level over 16 $\mathrm{mmol} / \mathrm{L}$, urinary albumin excretion $>30 \mathrm{mg} / 24 \mathrm{~h}$, and urine volume $>150 \%$ were considered to be diabetic with nephropathy [31]. Diabetic nephropathy rats were then followed for 8 weeks; the DN group received a saline placebo ( $1 \mathrm{ml} / \mathrm{kg}$ body weight QD PO for 8 weeks saline), and the Rapa group was treated with the mTOR inhibitor rapamycin (1 mg/kg body weight QD PO for 8 weeks) [32].

\section{Sample harvest}

Six animals from each group were sacrificed at week 2, week 4 and week 8. Body weight, fasting blood sugar, and $24 \mathrm{~h}$ urinary albumin were assessed. Blood samples were collected from the tail vein of overnight fasted rats. Urinary albumin was evaluated as a renal function parameter. Urine samples were collected by placing the animals in metabolic cages. Upon sacrifice, kidneys were harvested and weighed: left kidneys were fixed for immunohistochemistry, right kidneys were snap frozen in liquid nitrogen for western blot analysis and PCR testing.

Histology

Immediately after harvesting, the renal tissue was fixed in $10 \%$ formalin-buffered solution, embedded in paraffin, and sectioned to 2 - $\mu \mathrm{m}$ thickness. Hematoxylin and eosin (H\&E) and periodic acid Schiff (PAS) 


\section{Kidney Blood Pressure Research}

Yu/Bo/Villani/Spencer/Fu: The Effect of Rapamycin on TLR-4 and IL-17 in DN

staining were then performed. Glomerular cross-sectional tuft area (GA) was enumerated by light microscopy using an image analysis software (Image-proplus 6.0, Media Bybernetics). Mean glomerular volume (GV) of 30 consecutive fields (at $\times 400$ magnification) was calculated using the formula: $G A=(\beta / \mathrm{k}) \times(\mathrm{GA}) 3 / 2$, where $\mathrm{k}=1.1$ (size distribution coefficient) and $\beta=1.38$ (shape coefficient for spheres). In each glomerular tuft, mesangial area was defined as positive staining with PAS and mesangial matrix expansion index (MMEI) was calculated as follows: MMEI=Glomerular PAS positive area/GA. Glomerular basement membrane thickness was measured in at least 3 glomeruli per sample by means of electronic microscopy (x15000).

Immunohistochemistry

For TLR4 and IL-17 detection, slides were incubated overnight at $65^{\circ} \mathrm{C}$, then deparaffinized in xylene and dehydrated via a series of alcohol gradients. Endogenous peroxidase was deactivated by incubating with $3 \% \mathrm{H}_{2} \mathrm{O}_{2}$ at room temperature for $10 \mathrm{~min}$. Sections were then incubated with primary antibodies: rabbit anti-rat-TLR4 antibody (1:100)(Abcam, Cambridge, US), mouse anti- rat-IL-17 antibody (1:100) (Abcam, Cambridge,US) in moist chambers for $45 \mathrm{~min}$ at $37^{\circ} \mathrm{C}$. The slides were then washed in phosphate buffered saline (PBS) (pH 7.2-7.4), and incubated with the secondary antibody Envision ${ }^{\mathrm{TM}}$ Detection Systems Peroxidase/ Diaminobenzidine (DAB), Rabbit/Mouse (DAKO, Denmark) for 45 min. DAB kit (ZSGB-BIO, China) was applied for $2 \mathrm{~min}$ and then removed by rinsing with distilled water. Slides were counterstained with hematoxylin (Sigma, St. Louis, US). Sections were then mounted, and examined under light microscopy. Twenty randomly selected fields $(\times 400)$ were scanned per glomerulus. The epithelial cell membrane expression of TLR4 and IL-17 was quantified by using an Image-Pro Plus Image Analysis Software 6.0 (Media Cybernetics). The total integrated optical density (IOD), a parameter representing the expression levels of TLR-4 and IL-17 in renal tissue, was determined using a Bx41 cast-grid microscope with DP10 camera (Olympus, Tokyo, Japan), according to the method developed by Xavie et al [33]. Briefly, an area of interest in each section was first selected at 40× magnification. Optical density was calibrated and the area of interest was set as follows: hue, 0-30; saturation, 0-255; intensity, 0-20000. Then the values were counted $[34,35]$.

\section{Western blot analysis}

Renal tissues were incubated for 30 minutes in ice cold lysis buffer. The soluble fraction was then separated by centrifugation ( $12000 \mathrm{~g}$ for $20 \mathrm{~min}$ at $4^{\circ} \mathrm{C}$ ), and protein concentration measured using the BCA Protein Assay Kit (Pierce Biotechnology, Rockford, US). Proteins from lysates (30 $\mu \mathrm{g}$ ) were separated by $10 \%$ sodium dodecyl sulfate - polyacrylamide gel electrophoresis (SDS-PAGE) under non-reduced conditions, transferred to polyvinylidene fluoride (PVDF) membranes. Membranes were subsequently incubated with appropriate primary antibodies TLR4 (rabbit anti-rat-TLR4 antibody (1:100)(Abcam, Cambridge, US)into $5 \%$ bovine serum albumin (BSA)/tris-buffered saline (TBS) for one hour at room temperature, followed by one hour incubation with biotinlyated anti-goat, -mouse or -rabbit IgG (1:2000 dilution; Dako) and HRP-conjugated streptavidin (1:1000 dilution; Dako) for one hour. Immunoblotting was performed with peroxidase-labelled specific antibodies and visualized by Supersignal west pico chemiluminescent substrate kit(Pierce Biotechnology, Rockford, USA).

\section{Reverse transcription-polymerase chain reaction (RT-PCR)}

Primer sequences used for PCR amplification of cDNA are mentioned in Table 1. Renal tissue was homogenized with Trizol Reagent (Invitrogen, Grand Island, USA). The cDNA was amplified with specific primers for TLR-4 and GAPDH as a control. RNA was reverse-transcribed into cDNA using a Reverse Transcriptase cDNA Synthesis kit (Promega, Madison, USA) with oligo (dT) primer. The sample was incubated at $70^{\circ} \mathrm{C}$ for 5 minutes. After cooling down by placing on ice, the sample was incubated at $42^{\circ} \mathrm{C}$ for 60 minutes, and the M-MLV PCR Thermal Cycler (Promega Biotechnology, Madison, USA) was run 25 times. The cycles lasted for $30 \mathrm{~s}$ at $94^{\circ} \mathrm{C}$, for $30 \mathrm{~s}$ at $52^{\circ} \mathrm{C}$, and for $40 \mathrm{~s}$ at $72^{\circ} \mathrm{C}$ for TLR4 and the control gene GAPDH. The final incubation was at $72^{\circ} \mathrm{C}$ for $8 \mathrm{~min}$. Amplified PCR products were separated electrophoretically on a

Table 1.

\begin{tabular}{lll}
\hline Genes & Rats' PCR Sense primer & Rats' PCR Anti-sense primer \\
\hline TLR-4 & 5'-AGAAATTCCTGCAGTGGGTCA-3' & 5'-AGAAATTCCTGCAGTGGGTCA-3' \\
GAPDH & 5'-AACGACCCCTTCATTGAC-3' & 5'-TCCACGACATACTCAGCAC-3' \\
\hline
\end{tabular}




\section{Kidney Blood Pressure Research}

Table 2. Biochemical parameters in experimental animals

\begin{tabular}{lccc}
\hline & $\begin{array}{c}\text { Control } \\
(\mathrm{n}=6)\end{array}$ & $\begin{array}{c}\text { DN } \\
(\mathrm{n}=6)\end{array}$ & $\begin{array}{c}\text { DN with rapa } \\
(\mathrm{n}=6)\end{array}$ \\
\hline body weight $(\mathrm{g})$ & $420.0 \pm 8.92$ & $230.11 \pm 9.62^{*}$ & $200.20 \pm 7.50^{*}$ \\
Glucose $(\mathrm{mmol} / \mathrm{l})$ & $4.60 \pm 1.21$ & $30.2 \pm 10.21^{*}$ & $29.41 \pm 8.7^{*}$ \\
urinary albumin $(\mathrm{mg} / 24 \mathrm{~h})$ & $0.04 \pm 0.06$ & $100.50 \pm 7.71^{*}$ & $50.7 \pm 8.19^{*} \#$ \\
kidney K/W (mg/g) & $0.23 \pm 0.10$ & $0.42 \pm 0.03^{*}$ & $0.27 \pm 0.02 \#$ \\
\hline
\end{tabular}

The results are presented as the means \pm SEMs. Rapa group treated with rapamycin. Glucose had been collated by fasting blood sugar. *DN and Rapa vs. control, $\mathrm{P}<0.05$; \# Rapa vs. DN, $\mathrm{P}<0.05$

$1.0 \%$ agarose gel at $80 \mathrm{~V}$ for $20-30 \mathrm{mins}$, and bands were visualized with ethidium bromide under ultraviolet transillumination. Densitometry of PCR product to determine relative mRNA expression was performed with a System Sensitive Chemiluminescent Imaging System (FluorChem TM HD2, Alpha Innotech, San Jose, USA)

\section{Statistical Analysis}

Results of biological parameters were expressed as means \pm standard deviation. Groups were compared by one-way analysis of variance. Q-test (Student-Newman-Keuls multiple range test, SNK) was performed to compare multiple samples pairwise. Statistical analyses of differences between mean values were evaluated using a T-test. Pearson's correlation tests were performed to determine the degree of correlation between $\mathrm{K} / \mathrm{W}$ ratio and body weight or urinary albumin level in all the rats. The significance of differences in total IOD values was tested by Kruskal-Wallis analysis. $\mathrm{P}<0.05$ was considered statistically significant. Statistical analysis was performed using the SPSS 17.0 software (IBM, Cambridge, USA).

\section{Results}

\section{Rapamycin attenuated albuminuria}

All of the DN animals gained weight over time, although to a lesser extent than the nonDN control animals. The body weight of the Rapa group slightly increased at the first 2 weeks, but somewhat dropped in the following weeks. At the end of the experiment, we observed statistically significant levels of $24 \mathrm{~h}$ urinary albumin and kidney/body weight ratios in the DN and Rapa groups compared to the control animals. Significantly reduced albuminuria and kidney/body weight ratios were observed in Rapa group compared to DN group. The DN and Rapa animals had significantly higher glucose levels compared to the control animals $(P<0.05)$; there was no significant difference between the DN and Rapa group (Table 2).

\section{Rapamycin reduced glomerular hypertrophy and kidney injury}

The results of histopathological tests of the renal tissues from 2 to 8 weeks of age are shown in Figures 1-5. The glomeruli, tubules, and interstitial were studied by H\&E and PAS staining in the control, DN and Rapa groups. Glomerular hypertrophy is one of the early histological manifestations of DN. Glomerulosclerosis was characterized by an increase in size of the glomerulus and the mesangial expansion from 2 week of age. Pathological renal lesion significantly worsened with time (Figure 1). At the end of experiment 8 weeks of age, glomerulosclerosis was characterized by an obvious growth of GV in DN group while MMEI distinctly rising (Figure 7). All these differences have statistical significance $(\mathrm{P}<0.05)$. The collapse and occlusion of glomerulocapillary wall, showed partly diffuse thickening and segmental fibrosis in severe cases by electron microscopy (Figure2, 7). Rapamycin relieved glomerular hypertrophy and mesangial expansion (Figure 1). Tubular lesions included tubular regeneration, dilatation, and hyaline casts, and interstitial lesions included fibrosis and inflammatory cell infiltration. 


\section{Kidney Blood Pressure Research}

Fig. 1. The pathologic changes on renal tissue in 3 groups (A-F: HE staining, a-f: PAS staining. $x$ 400). A/a: normal glomerulus of control group; $\mathrm{B} / \mathrm{b}$ : glomerulus of 2 weeks of age in DN group; $\mathrm{C} / \mathrm{c}$ : glomerulus of 4 weeks of age in DN group; D/d: glomerulus of 8 weeks of age in DN group; E/e: glomerulus of 4 weeks of age in Rapa group with the dose of $1 \mathrm{mg} / \mathrm{kg} / \mathrm{d}$; $\mathrm{F} / \mathrm{f}$ : glomerulus of 8 weeks of age in Rapa group.

Fig. 2. The electron microscope results of glomeruli. A: normal glomerular basement membrane,(GBM) , B:GBM of $\mathrm{DN}, \mathrm{C}$ : the collapse and occlusion of glomerulocapillary endothelial cells.
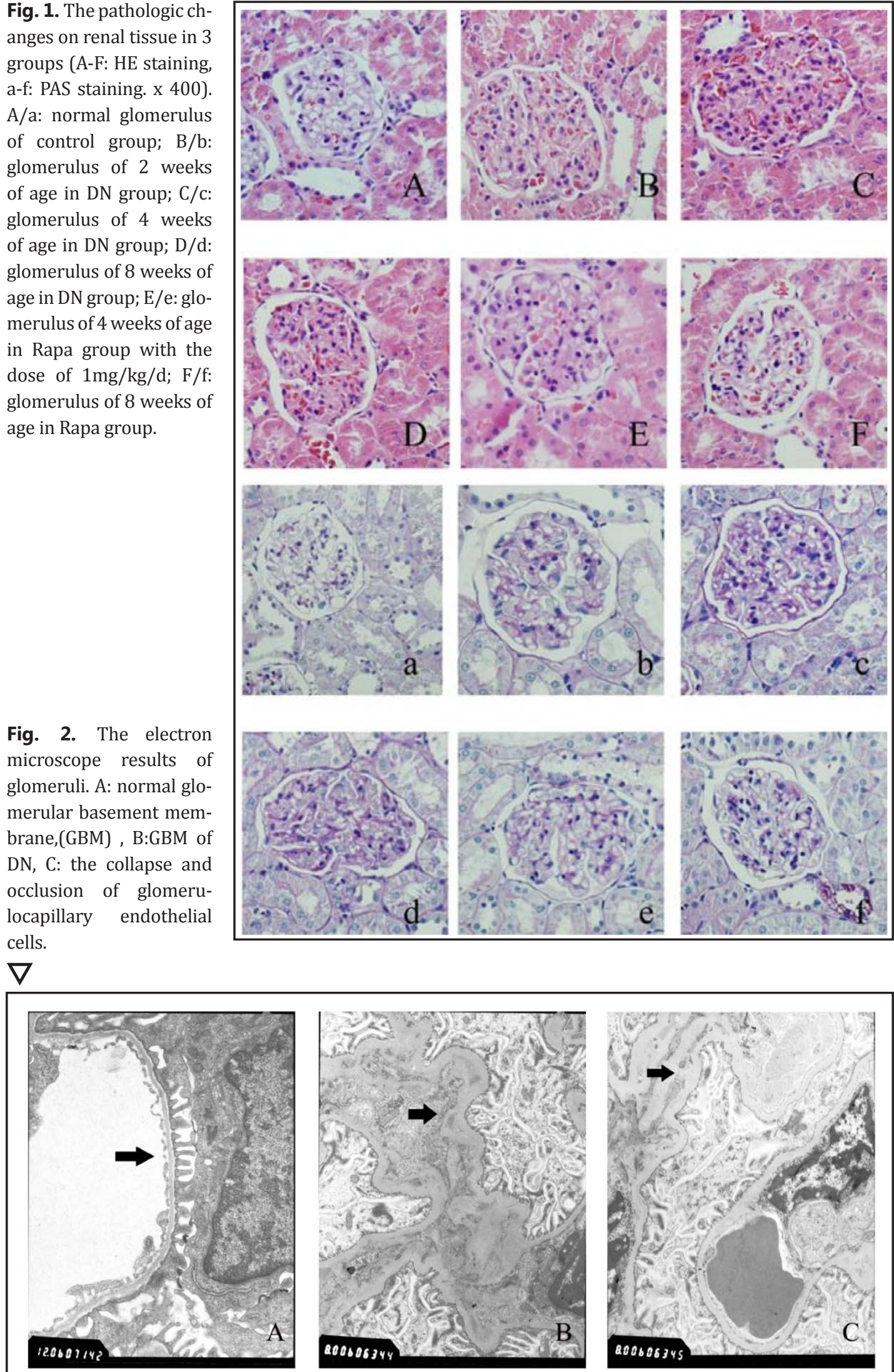

KARGER 


\section{Kidney Blood Pressure Research}

Fig. 3. Immunohistochemical result of TLR4 in every group. (x400) A: Control group; B,C \& D: respectively showed DN 2, 4 and 8 weeks; E \& F: severally denoted 4 and 8 weeks after rapamycin treatment.

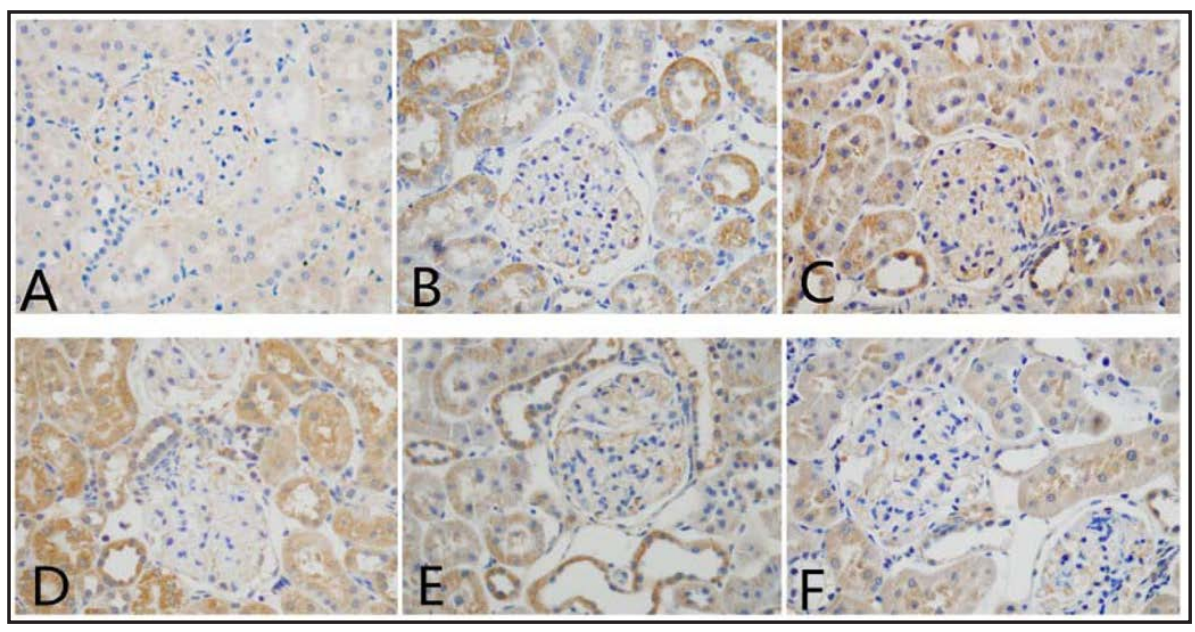

Expression of TLR4 protein and $m R N A$ was upregulated and reduced by rapamycin in early stages of DN. A spot of TLR4 was expressed on the normal renal tissue from control rats, positioned on renal tubular epithelial cells. Compared with controls, TLR4 protein expression of DN group was distinctly upregulated, pitching on mesangial cells and renal tubular epithelial cells (Figure3). TLR4 protein quantity was tested by western-blot semiquantitative analysis. In comparison with controls, the expression of TLR4 gradually increased in the DN beginning 2 weeks after diabetes induction. Samples at 4 and 8 weeks had a significantly higher expression of TLR4 protein $(P<0.05)$. After 4 and 8 weeks of treatment with rapamycin, the expression of TLR4 protein decreased in the Rapa group (DN vs Rapa $P<0.05$ ) (Figure 4) TLR4 mRNA expression in

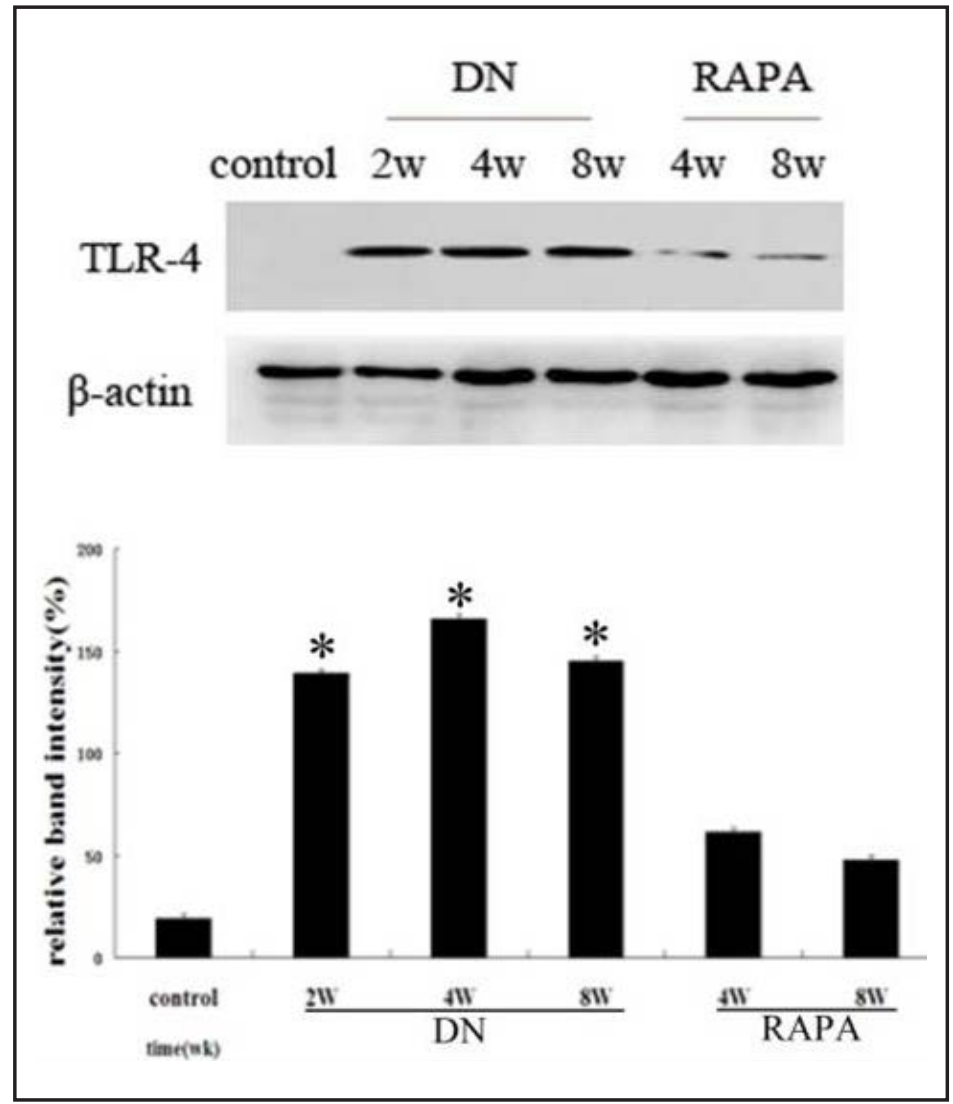

Fig. 4. The results of all 3 groups were detected by Western-blot method. Control was normal group. DN mean diabetic nephropathy group. Rapa stood for rapamycin treatment after setting of DN model. The data were analyzed by relative band intensity. * DN versus control and Rapa group, $\mathrm{p}<0.05$.

the whole kidney was also elevated at 2,4 , and 8 weeks in DN rats compared to controls $(P<0.05)$. In the Rapa group the level of TLR4 mRNA was not statistically different from the control group ( $P>0.05$, Figure 5). IOD was used as a parameter of quantification TLR4 protein expression. 


\section{Kidney Blood Pressure Research}

At 2, 4 and 8 weeks, the average TLR4 IOD of the DN group was significantly increased compared to the controls $(\mathrm{P}<0.05)$. At 4 and 8 weeks, the Rapa TLR4 IOD was markedly reduced when compared to the DN group $(\mathrm{P}<0.05$, Table 3$)$.
Table 3. IOD expression of TLR4 was upregulated and reduced by rapamycin in early stage of DN

\begin{tabular}{cccc}
\hline & Control & DN & Rapa \\
\hline 2W & $7361.7 \pm 1327.4$ & $9654.5 \pm 2144.3^{*}$ & $/$ \\
4W & $7742.3 \pm 2132.8$ & $12793.5 \pm 1898.2^{*}$ & $8675.3 \pm 2295.4^{*} \#$ \\
8W & $7593.6 \pm 1973.2$ & $13972.4 \pm 2930.7^{*}$ & $8189.1 \pm 2743.6^{*} \#$ \\
\hline
\end{tabular}

The results are presented as the means \pm SEMs. Rapa group treated with rapamycin. ${ }^{*} \mathrm{DN}$ and Rapa vs. control, $\mathrm{P}<0.05$; \# Rapa vs. DN, $\mathrm{P}<0.05$

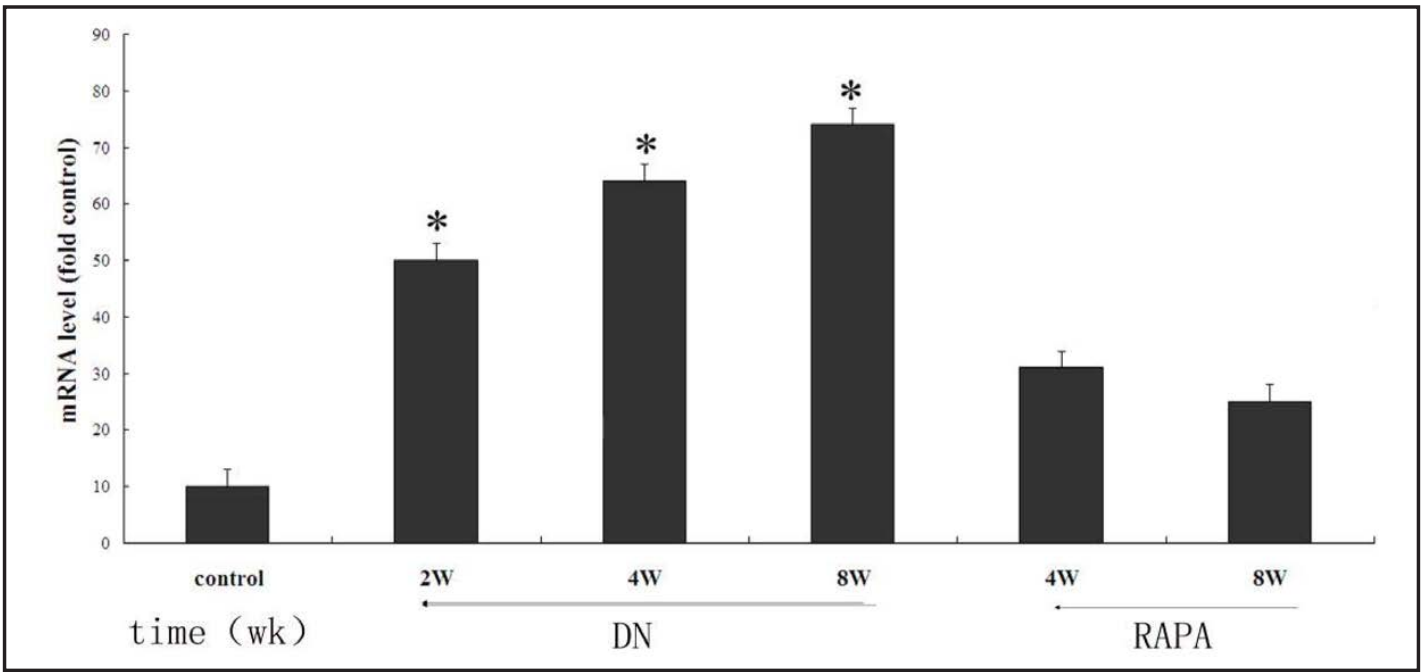

Fig. 5. TLR4 mRNA level were tested by PCR. Control was normal group. DN mean diabetic nephropathy group. Rapa stood for rapamycin treatment after setting of DN model. * DN versus control and Rapa group, $\mathrm{p}<0.05$.

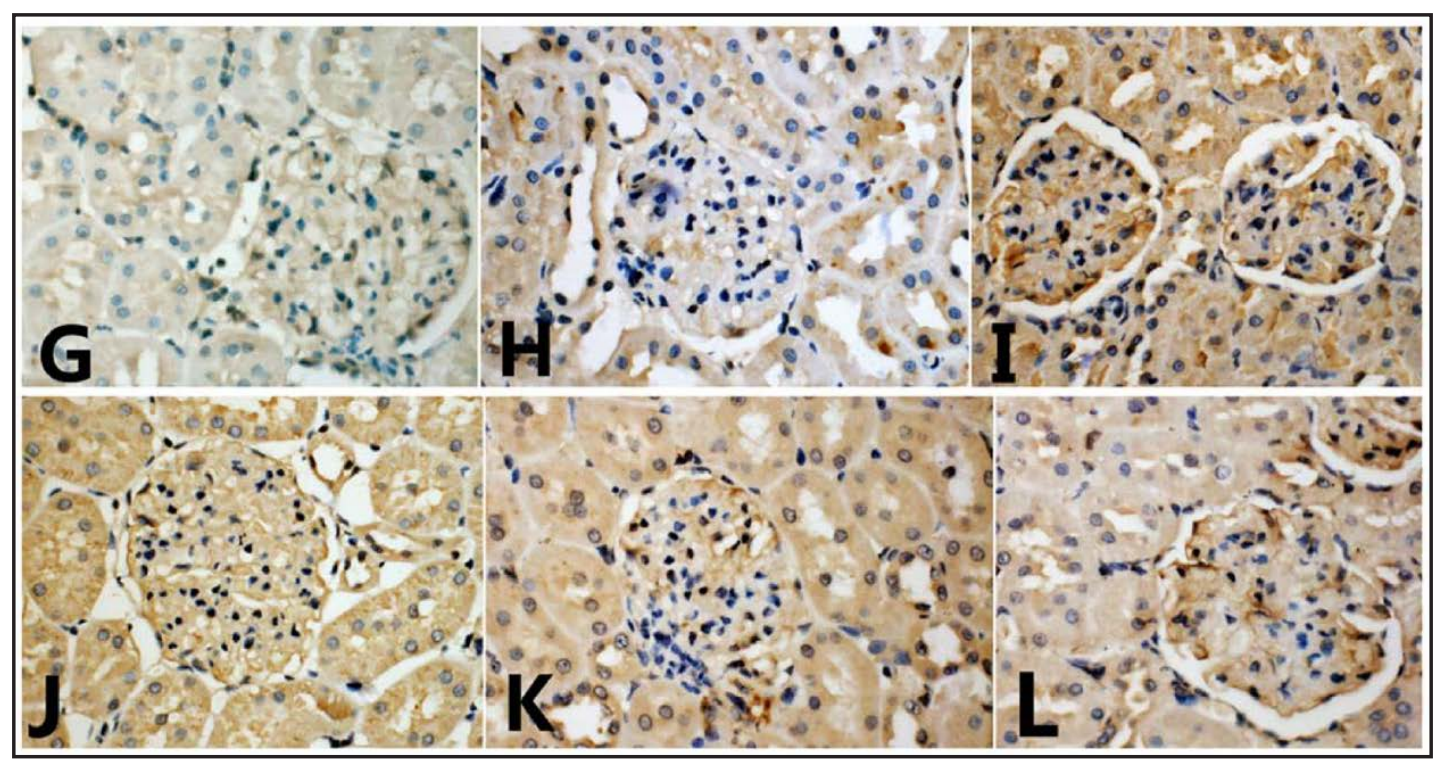

Fig. 6. Immunohistochemical result of IL-17 in all 3 groups (x400). G: Control group; H, I \& J: respectively showed DN 2, 4 and 8 weeks; K \& L: severally denoted 4 and 8 weeks after rapamycin treatment. 


\section{Kidney Blood Pressure Research}

Fig. 7. Histogram showed the comparison of GV and MMEI between DN and control groups, ${ }^{*} \mathrm{p}<0.05$. The comparison of thickness of glomerular basement membrane (GBMT). The mean of DN group's GBMT is obviously greater than that of control group, $\mathrm{p}<0.05$.

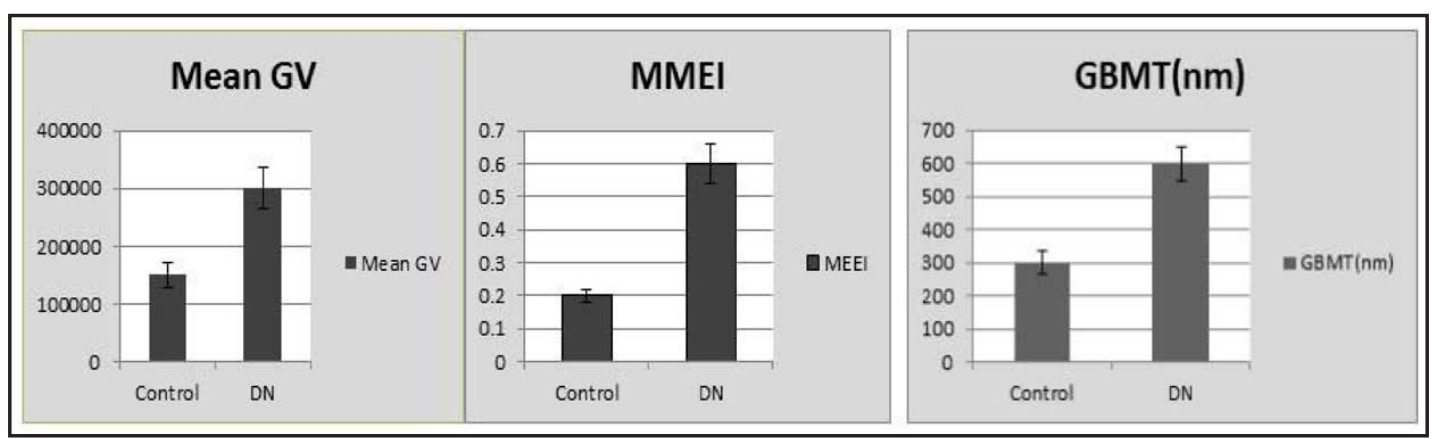

Table 4. IOD expression of IL-17 was upregulated in diabetic groups and reduced by rapamycin in early stage of DN

\begin{tabular}{cccc}
\hline & Control & DN & Rapa \\
\hline 2W & $5285.0 \pm 1139.6$ & $8236.5 \pm 1148.9^{*}$ & $/$ \\
$4 \mathrm{~W}$ & $5749.2 \pm 1386.4$ & $9337.4 \pm 1022.2^{*}$ & $7071.4 \pm 1105.8^{*} \#$ \\
$8 \mathrm{~W}$ & $5952.4 \pm 1832.9$ & $10834.7 \pm 1730.0^{*}$ & $6942.3 \pm 1537.6^{*} \#$ \\
\hline
\end{tabular}

The results are presented as the means \pm SEMs. Rapa group treated with rapamycin. *DN and Rapa vs. control, $\mathrm{P}<0.05$; \# Rapa vs. DN, $\mathrm{P}<0.05$
Expression of IL-17 protein was upregulated and reduced by rapamycin in early stage of $D N$.

Similarly to TLR4, IL-17 expression was also increased in the DN group at weeks 2, 4 and 8 $(P<0.05)$. Rapamycin administration significantly reduced the degree of increase in IL-17 IOD at weeks 4 and $8(P<0.05$, Figure6, Table 4).

Correlation Analysis: Pearson correlation coefficients between TLR4, IL-17 IOD and renal function index

TLR4 and IL-17 IOD of rats' renal tissue were analyzed by Pearson correlation coefficients. TLR4 and IL-17 IOD level positively correlated to the renal functions index including $24 \mathrm{~h}$ urinary albumin $(\mathrm{P}<0.05)$, kidney/weight ratio $(\mathrm{P}<0.01)$. Also there was a strong correlation in TLR4 and IL-17 values $(\mathrm{P}<0.01)$. However, neither TLR4 IOD nor IL-17 IOD correlated with fasting blood sugar ( $P>0.05$, Table 5).

\section{Discussion}

The high glucose conditions are coupled with increases in proinflammatory cytokines from macrophages, monocytes, and dendritic cells [36]. Our study showed that DN rats upregulate TLR4 in glomeruli, and have an increase in the expression of pro-inflammatory factor IL-17 along with an increase of urinary albumin. 24-hour urinary albumin is a significant clinical hallmark of early stages diabetic nephropathy. The histological correlation of albuminuria includes glomerular hypertrophy, mesangial expansion, glomerular basement membrane thickness, glomerulosclerosis, and the collapse and
Table 5. Correlation Analysis between TLR4, IL17 IOD and renal function index

\begin{tabular}{lcc}
\hline TLR4 IOD & R1 & P \\
\hline IL17 IOD & 0.99 & $<0.01$ \\
urinary albumin & 0.94 & $<0.05$ \\
Fasting glucose & 0.67 & $>0.05$ \\
Kidney K/W & 0.99 & $<0.01$ \\
IL17 IOD & R2 & P \\
TLR4 IOD & 0.99 & $<0.01$ \\
urinary albumin & 0.90 & $<0.05$ \\
Fasting glucose & 0.59 & $>0.05$ \\
Kidney K/W & 0.99 & $<0.01$ \\
\hline
\end{tabular}




\section{Kidney Blood Pressure Research}

Kidney Blood Press Res 2016;41:55-69

\begin{tabular}{l|l}
\hline DOI: 10.1159/000368547 & (C) 2016 The Author(s). Published by S. Karger AG, Basel
\end{tabular}

Published online: February 07, 2016

www.karger.com/kb

Yu/Bo/Villani/Spencer/Fu: The Effect of Rapamycin on TLR-4 and IL-17 in DN

occlusion of glomerulocapillary endothelial cells, all of which were observed in our model. One limitation of our study is that these changes are present to a lesser degree in rodent models of diabetic nephropathy as compared to human samples. This has to be taken in account when interpreting our experimental findings. However, even though the severity of the histological lesions is less severe in rodents as compared to humans, rodent models can still provide useful mechanistic insights in the development of diabetic nephropathy in humans. Several findings based on STZ-induced rodent models of diabetes have been confirmed in human patients [37]. For this reason our findings will need to be validated in a study based on clinical human samples.

Our study provides additional evidence in support of the hypothesis that inflammatory and immunological processes play a fundamental role in the development and progression of DN.

\section{$T L R-4$}

Previous studies revealed that hyperglycemia induced expression and activation of TLR4 mediated inflammatory pathways [38]. Since TLR4 is a classical immune receptor, a previous study demonstrated TLR4 knockout DN mice leads to a dramatic reduction in circulating and macrophage biomarkers of inflammation [17].

Interestingly, we found a spot of TLR4 was expressed on the normal renal tissue from control rats, positioned on renal tubular epithelial cells. This result confirms with the previous study that there was minimal staining in the kidneys of the STZ-TLR4 knockout mice [17]. Compared with controls, TLR4 protein expression of DN group was distinctly up-regulated, pitching on mesangial cells and renal tubular epithelial cells. With respect to TLR4, data also support increased expression of in the DN mice appeared to be mostly in the tubulo-interstitial area [17]. After treatment with rapamycin, the expression of TLR4 protein decreased in the Rapa group. Consequently, our novel findings of a beneficial effect of rapamycin on early stage of DN via TLR4 pathway in vivo, confirms a role of TLR4 in renal fibrosis, a dangerous factor of DN. Our findings also support Luo et al who suggest that TLR4driven mTOR signaling plays a vital role in innate immune responses [39].

Here we have demonstrated the activation of TLR4 in renal tubular epithelial cells in DN rats. This result is compatible with a recent research in humans where upregulation of TLR in renal tubules correlated with monocyte and macrophage gathering in DN [13]. Hyperglycemia is known to stimulate TLR4 expression in monocytes from patients with diabetes $[40,41]$. TLR4 can initiate NF-KB-dependent inflammation via MyD88 signal pathway. All these changes were reduced by mTOR inhibitor rapamycin in our study, which is consistent with a recent study showing the TLR4-mediated production is dependent on the PI3K/mTOR/p70S6 kinase pathway [42].

TLR4 has an important impact in the innate immune responses in sterile inflammation of diabetic nephropathy. In this study, we confirmed that TLR4 signaling pathway was activated in DN rats which were induced by streptozocin. DN rats treated by rapamycin were protected from kidney inflammation, glomerular and tubular injury, interstitial fibrosis and albuminuria. Taken together, our study suggests that activation of TLR4 has a striking effect on the early stage development of DN, and could be suppressed by mTOR inhibitor rapamycin. It opens up a new avenue of research investigating strategies aimed at reducing renal inflammation and fibrosis through TLR4 inhibition by rapamycin.

\section{$I L-17$}

There is rising evidence that the inflammatory role in DN involves the activation of both innate and adaptive immunities $[43,44]$. However, the role of pro-inflammatory T helper 17 cells in the development and progression of DN is unclear. Some studies reported the 


\section{Kidney Blood Pressure Research}

Kidney Blood Press Res 2016;41:55-69

\begin{tabular}{l|l}
\hline DOI: 10.1159/000368547 & (C) 2016 The Author(s). Published by S. Karger AG, Basel
\end{tabular}

Published online: February 07, 2016

www.karger.com/kb

essential function of Th17 signal pathway is not only through inflammation but may also via chronic sterile inflammation in metabolic disease [45].

Our result showed that similarly to TLR4, IL-17 expression was also increased in the DN group at weeks 2, 4 and 8. The mesangial cells and proximal tubular cells have IL-17 receptors and secret downstream cytokines by responding to IL-17 [46-48]. These cytokines accelerate renal recruitments of monocytes and lymphocytes, which may be linked with the development of immune-mediated renal damage. This result indicates that Thelper 17 may play an independent role in the progression of DN and modulation of IL-17 is a potential immunologic therapeutic target. Interestingly, the effect of IL-17 regulation in the Type 1 diabetes (T1D) is equivocal. The literatures had shown that increased Th17 cells, which were induced by bacteria or by adjuvant immunotherapy can postpone the onset of T1D [49-51]. On the other hand, some researchers reported that pediatric diabetic patients who have newly diagnosed T1D have an increased number of Th17 cells [52, 53]. Furthermore, blocking IL-17 after the early stage has a robust protective effect in T1D mice [54]. One explanation for these contradictory findings may be that Th17 cells initially play a protective role. However, after playing a beneficial role initially, high levels of Th17 cells can then contribute to the development of disease at a later time point.

Our data also demonstrates that 8-week old Rapa group rats have a noteworthy decrease of IL-17 on renal tissue when compared with 8-week-old DN rats. Targeting IL17-producing cells by rapamycin in DN attenuates mesangial sclerosis, tubulointerstitial fibrosis, and urinary albumin excretion independent of glycemic control. The IL-17 positive cells were notably amplified in the kidneys of diabetic rats compared with the kidney cells modulating Th17 by rapamycin is related with a reduction in albuminuria. It is exciting to find that intrarenal Th17 was augmented, and it was suppressed by rapamycin treatment during the early stage of DN.

\section{Correlation between TLR4 and IL-17 in DN}

TLR signaling pathway may enhance the process of autoimmunity by several mechanisms. TLR signaling promotes the antigen-presenting capacity (APC) to CD4+ T cells via increasing of HLA-DR [55]. CD4+T cells are divided into Th1, Th2 and Th17 cells as charcterized by the secretion of cytokines IFN $\gamma$, IL-4, and IL-17 [56-58]. Activation of TLR2 might induce Th2 immune response, TLR4 induces Th1 and Th17 immune response, and TLR9 induces Th1 immune response [59-66]. We showed that the expression level of TLR4 was higher compared to controls and had a significant positive correlation with IL-17. This result suggests that the overexpression of TLR4 might be involved in the immunopathogenesis of DN through activation of Th17 cells.

According to recent studies and to our data, the possible immunopathogenic involvement of TLR4 and Th17 cells is the following: (1) overexpression of TLR4 induced by microbial pathogen, endogenous molecules, and inflammatory cytokines contributes to activation of CD4+ T cells resulting in up-regulation of IL-17; (2) overexpression of CD4+ $\mathrm{T}$ cells cytokines induces the inflammatory response, leading to an increase of various inflammatory cytokines and endogenous molecules; (3) overexpression of CD4+T-cell and inflammatory cytokines, including IL-17 induces the overexpression of TLR4, causing the vicious cycle of amplification of chronic inflammation in the renal tissue in DN [37].

\section{Conclusion}

Our results confirm and expand previous studies identifying TLR4 as a mediator of development of early stage DN. Our data and also suggests that TLR4 may affect the 


\section{Kidney \\ Blood Pressure Research}

Yu/Bo/Villani/Spencer/Fu: The Effect of Rapamycin on TLR-4 and IL-17 in DN

Th17 pathway function in the progression of renal damage. In addition, during the immunopathogenesis of early stage DN, the overexpression of TLR4 might be induced by activation of Th17 cells. Rapamycin may attenuate DN via reduction of the TLR4 signaling pathway and Th17 cells signaling. Given the contribution of TLR4 pathways and the proinflammatory function of IL-17 in these essential stages of diabetic nephropathy, future studies on TLR4 and IL-17 signaling will be essential to develop effective therapeutic strategies for the treatment of early DN.

\section{Disclosure Statement}

The authors declare that they have no competing interests.

\section{Abbreviations}

Akt/PKB: protein kinase B, APC: antigen-presenting capacity, BSA: bovine serum albumin, DAB: Diaminobenzidine, DN: Diabetic nephropathy, ESKD: end-stage kidney disease, FKBP 12: FK506-binding protein 12, FRB: FKBP12-Rapamycin Binding, GA: Glomerular cross-sectional tuft area, GV: glomerular volume, H\&E: Hematoxylin and eosin, IFN- $\gamma$ : interferon- $\gamma$, IL-17: Interleukin 17, IRAK4: interleukin-1 receptor-associated kinase 4, IRI: ischemia-reperfusion injury, LN: lupus nephritis, MMEI: mesangial matrix expansion index, mTOR: mammalian target of rapamycin, NF-kB: nuclear factor kappa-light-chain-enhancer of activated B cells, NF- $\kappa B$ : nuclear factor $\kappa B$, PAS: periodic acid Schiff, PBS: phosphate buffered saline, PI3K: phosphatidylinositol 3-kinase, PVDF: polyvinylidene fluoride, Rapa: rapamycin treated, RT-PCR: Reverse transcription-polymerase chain reaction, SD: Sprague-Dawley, STZ: streptozocin, T1D: Type 1 diabetes, TBS: tris-buffered saline, TEC: tubular endothelial cell, TECs: tubular epithelial cells, TGF- $\beta$ : transforming growth factor- $\beta$, Th17: T helper 17 cells, TLRs: Toll-like receptors, TNF- $\alpha$ : tumor necrosis factor- $\alpha$.

\section{Acknowledgments}

This study was funded by National Natural Science Foundation of China (Funding number: 30771005).

\section{References}

1 White SL, Cass A, Atkins RC, Chadban SJ: Chronic kidney disease in the general population. Adv Chronic Kidney Dis 2005;12:5-13.

2 Gilbert RE, Cooper ME: The tubulointerstitium in progressive diabetic kidney disease: more than an aftermath of glomerular injury? Kidney Int 1999;56:1627-1637.

3 Mora C, Navarro JF: Inflammation and diabetic nephropathy. Curr Diab Rep 2006;6:463-468.

4 Tuttle KR: Linking Metabolism and Immunology: Diabetic Nephropathy Is an Inflammatory Disease. J Am Soc Nephrol 2005;16:1537-1538.

5 Wada J, Makino H: Inflammation and the pathogenesis of diabetic nephropathy. Clin Sci (Lond) 2013;124:139-152.

6 Fornoni A, Ijaz A, Tejada T, Lenz 0: Role of inflammation in diabetic nephropathy. Curr Diabetes Rev 2008;4:10-17.

$7 \quad$ Galkina E, Ley K: Leukocyte recruitment and vascular injury in diabetic nephropathy. J Am Soc Nephrol 2006;17:368-377. 


\section{Kidney \\ Blood Pressure Research}

8 Nguyen DUY, Ping FU, Mu WEI, Hill P, Atkins RC, Chadban SJ: Macrophage accumulation in human progressive diabetic nephropathy. Nephrology 2006;11:226-231.

9 Burton CJ, Combe C, Walls J, Harris KP: Secretion of chemokines and cytokines by human tubular epithelial cells in response to proteins. Nephrol Dial Transplant 1999;14:2628-2633.

10 Lai KN, Leung JC, Chan LY, Guo H, Tang SC: Interaction between proximal tubular epithelial cells and infiltrating monocytes/T cells in the proteinuric state. Kidney Int 2007;71:526-538.

11 Nakajima H: Activation of the Signal Transducer and Activator of Transcription Signaling Pathway in Renal Proximal Tubular Cells by Albumin. J Am Soc Nephrol 2004;15:276-285.

12 Akira S, Takeda K: Toll-like receptor signalling. Nat Rev Immunol 2004;4:499-511.

13 Lin M, Yiu WH, Wu HJ, Chan LYY, Leung JCK, Au WS, Chan KW, Lai KN, Tang SCW: Toll-Like Receptor 4 Promotes Tubular Inflammation in Diabetic Nephropathy. J Am Soc Nephrol 2011;23:86-102.

14 Banas MC, Banas B, Hudkins KL, Wietecha TA, Iyoda M, Bock E, Hauser P, Pippin JW, Shankland SJ, Smith KD, Stoelcker B, Liu G, Grone HJ, Kramer BK, Alpers CE: TLR4 Links Podocytes with the Innate Immune System to Mediate Glomerular Injury. J Am Soc Nephrol 2008;19:704-713.

15 Jialal I, Major AM, Devaraj S: Global toll-like receptor 4 knockout results in decreased renal inflammation, fibrosis and podocytopathy. J Diabetes Complications 2014;28:755-761.

16 Devaraj S, Jialal I, Yun J-M, Bremer A: Demonstration of increased toll-like receptor 2 and toll-like receptor 4 expression in monocytes of type 1 diabetes mellitus patients with microvascular complications. Metabolism 2011;60:256-259.

17 Devaraj S, Tobias P, Jialal I: Knockout of toll-like receptor-4 attenuates the pro-inflammatory state of diabetes. Cytokine 2011;55:441-445.

18 Kish DD, Li X, Fairchild RL: CD8 T Cells Producing IL-17 and IFN- Initiate the Innate Immune Response Required for Responses to Antigen Skin Challenge. J Immunol 2009;182:5949-5959.

19 Häcker G, Paustian C, Taylor P, Johnson T, Xu M, Ramirez N, Rosenthal KS, Shu S, Cohen PA, Czerniecki BJ, Koski GK: Extracellular ATP and Toll-Like Receptor 2 Agonists Trigger in Human Monocytes an Activation Program That Favors T Helper 17. PLoS ONE 2013;8:e54804.

20 Qin Y, Sun Y-T, Xia L-X, Zhang Y-J, Yang X-J: Effect of simvastatin on expression of IL17, HMGB1 and TLR4 in LN kidney tissues of rats. Asian Pac J Trop Med 2014;7:792-795.

21 Dong X, Bachman LA, Miller MN, Nath KA, Griffin MD: Dendritic cells facilitate accumulation of IL-17 T cells in the kidney following acute renal obstruction. Kidney Int 2008;74:1294-1309.

22 Kim Y-G, Kim E-Y, Ihm C-G, Lee T-W, Lee S-H, Jeong K-h, Moon J-Y, Chung J-H, Kim Y-H: Gene Polymorphisms of Interleukin-17 and Interleukin-17 Receptor Are Associated with End-Stage Kidney Disease. Am J Nephrol 2012;36:472-477.

23 Hay N, Sonenberg N: Upstream and downstream of mTOR. Genes Dev 2004;18:1926-1945.

24 Beevers CS, Li F, Liu L, Huang S: Curcumin inhibits the mammalian target of rapamycin-mediated signaling pathways in cancer cells. Int J Cancer 2006;119:757-764.

25 Huang S, Bjornsti MA, Houghton PJ: Rapamycins: mechanism of action and cellular resistance. Cancer Biol Ther 2003;2:222-232.

26 Devaraj S, Dasu MR, Rockwood J, Winter W, Griffen SC, Jialal I: Increased Toll-Like Receptor (TLR) 2 and TLR4 Expression in Monocytes from Patients with Type 1 Diabetes: Further Evidence of a Proinflammatory State. J Clin Endocrinol Metab 2008;93:578-583.

27 Eiró N, González-Reyes S, González L, González LO, Altadill A, Andicoechea A, Fresno-Forcelledo MF, Rodrigo-Sáez L, Vizoso FJ: Duodenal Expression of Toll-Like Receptors and Interleukins Are Increased in Both Children and Adult Celiac Patients. Dig Dis Sci 2012;57:2278-2285.

28 Pan H, O'Brien TF, Wright G, Yang J, Shin J, Wright KL, Zhong XP: Critical Role of the Tumor Suppressor Tuberous Sclerosis Complex 1 in Dendritic Cell Activation of CD4 T Cells by Promoting MHC Class II Expression via IRF4 and CIITA. J Immunol 2013;191:699-707.

29 Mudaliar H, Pollock C, Komala MG, Chadban S, Wu H, Panchapakesan U: The role of Toll-like receptor proteins (TLR) 2 and 4 in mediating inflammation in proximal tubules. Am J Physiol Renal Physiol 2013;305:F143-154.

30 Dieckmann A, Kriebel M, Andriambeloson E, Ziegler D, Elmlinger M: Treatment with Actovegin(R) improves sensory nerve function and pathology in streptozotocin-diabetic rats via mechanisms involving inhibition of PARP activation. Exp Clin Endocrinol Diabetes 2012;120:132-138. 


\section{Kidney \\ Blood Pressure Research}

Kidney Blood Press Res 2016;41:55-69

\begin{tabular}{l|l}
\hline DOI: 10.1159/000368547 & (C) 2016 The Author(s). Published by S. Karger AG, Base
\end{tabular}

Published online: February 07, 2016 www.karger.com/kbr

Yu/Bo/Villani/Spencer/Fu: The Effect of Rapamycin on TLR-4 and IL-17 in DN

31 del Cañizo Gómez FJ, Fernández Pérez C, Moreno Ruiz I, de Gorospe Pérez-Jáuregui C, Silveira Rodríguez B, González Losada T, Segura Galindo A: Microvascular complications and risk factors in patients with type 2 diabetes. Endocrinol Nutr 2011;58:163-168.

32 Wittmann S, Daniel C, Stief A, Vogelbacher R, Amann K, Hugo C: Long-Term Treatment of Sirolimus but Not Cyclosporine Ameliorates Diabetic Nephropathy in the Rat. Transplantation 2009;87:1290-1299.

33 Xavier LL, Viola GG, Ferraz AC, Da Cunha C, Deonizio JMD, Netto CA, Achaval M: A simple and fast densitometric method for the analysis of tyrosine hydroxylase immunoreactivity in the substantia nigra pars compacta and in the ventral tegmental area. Brain Res Brain Res Protoc 2005;16:58-64.

34 Dong J, Yin H, Liu W, Wang P, Jiang Y, Chen J: Congenital iodine deficiency and hypothyroidism impair LTP and decrease C-fos and C-jun expression in rat hippocampus. Neurotoxicology 2005;26:417-426.

35 van Kuijk AWR, Gerlag DM, Vos K, Wolbink G, de Groot M, de Rie MA, Zwinderman AH, Dijkmans BAC, Tak PP: A prospective, randomised, placebo-controlled study to identify biomarkers associated with active treatment in psoriatic arthritis: effects of adalimumab treatment on synovial tissue. Ann Rheum Dis 2008;68:1303-1309.

36 Kim S-M, Lee S-H, Lee A, Kim D-J, Kim Y-G, Kim S-Y, Jeong K-H, Lee T-W, Ihm C-G, Lim S-J, Moon J-Y: Targeting T helper 17 by mycophenolate mofetil attenuates diabetic nephropathy progression. Transl Res 2015;166:375-383.

37 Tesch GH, Allen TJ: Rodent models of streptozotocin-induced diabetic nephropathy (Methods in Renal Research). Nephrology 2007;12:261-266.

38 Deshpande SD, Putta S, Wang M, Lai JY, Bitzer M, Nelson RG, Lanting LL, Kato M, Natarajan R: Transforming growth factor-beta-induced cross talk between p53 and a microRNA in the pathogenesis of diabetic nephropathy. Diabetes 2013;62:3151-3162.

39 Luo L, Wall AA, Yeo JC, Condon ND, Norwood SJ, Schoenwaelder S, Chen KW, Jackson S, Jenkins BJ, Hartland EL, Schroder K, Collins BM, Sweet MJ, Stow JL: Rab8a interacts directly with PI3K $\gamma$ to modulate TLR4driven PI3K and mTOR signalling. Nat Commun 2014;5:4407.

40 Dasu MR, Devaraj S, Park S, Jialal I: Increased Toll-Like Receptor (TLR) Activation and TLR Ligands in Recently Diagnosed Type 2 Diabetic Subjects. Diabetes Care 2010;33:861-868.

41 Kriegel MA, Sefik E, Hill JA, Wu HJ, Benoist C, Mathis D: Naturally transmitted segmented filamentous bacteria segregate with diabetes protection in nonobese diabetic mice. Proc Natl Acad Sci USA 2011;108:11548-11553.

42 Papadimitraki ED, Bertsias GK, Boumpas DT: Toll like receptors and autoimmunity: A critical appraisal. J Autoimmun 2007;29:310-318.

43 Hotamisligil GS: Inflammation and metabolic disorders. Nature 2006;444:860-867.

44 Akash MSH, Rehman K, Chen S: Role of inflammatory mechanisms in pathogenesis of type 2 diabetes mellitus. J Cell Biochem 2013;114:525-531.

45 von Vietinghoff S, Koltsova EK, Mestas J, Diehl CJ, Witztum JL, Ley K: Mycophenolate Mofetil Decreases Atherosclerotic Lesion Size by Depression of Aortic T-Lymphocyte and Interleukin-17-Mediated Macrophage Accumulation. J Am Coll Cardiol 2011;57:2194-2204.

46 Van Kooten C, Boonstra JG, Paape ME, Fossiez F, Banchereau J, Lebecque S, Bruijn JA, De Fijter JW, Van Es LA, Daha MR: Interleukin-17 activates human renal epithelial cells in vitro and is expressed during renal allograft rejection. J Am Soc Nephrol 1998;9:1526-1534.

47 Paust HJ, Turner JE, Steinmetz OM, Peters A, Heymann F, Holscher C, Wolf G, Kurts C, Mittrucker HW, Stahl RAK, Panzer U: The IL-23/Th17 Axis Contributes to Renal Injury in Experimental Glomerulonephritis. J Am Soc Nephrol 2009;20:969-979.

48 Iyoda M, Shibata T, Kawaguchi M, Hizawa N, Yamaoka T, Kokubu F, Akizawa T: IL-17A and IL-17F stimulate chemokines via MAPK pathways (ERK1/2 and p38 but not JNK) in mouse cultured mesangial cells: synergy with TNF-alpha and IL-1beta. Am J Physiol Renal Physiol 2010;298:F779-787.

49 Lau K, Benitez P, Ardissone A, Wilson TD, Collins EL, Lorca G, Li N, Sankar D, Wasserfall C, Neu J, Atkinson MA, Shatz D, Triplett EW, Larkin J: Inhibition of Type 1 Diabetes Correlated to a Lactobacillus johnsonii N6.2-Mediated Th17 Bias. J Immunol 2011;186:3538-3546.

50 Nikoopour E, Schwartz JA, Huszarik K, Sandrock C, Krougly O, Lee-Chan E, Singh B: Th17 Polarized Cells from Nonobese Diabetic Mice Following Mycobacterial Adjuvant Immunotherapy Delay Type 1 Diabetes. J Immunol 2010;184:4779-4788. 


\section{Kidney \\ Blood Pressure Research}

51 Ferraro A, Socci C, Stabilini A, Valle A, Monti P, Piemonti L, Nano R, Olek S, Maffi P, Scavini M, Secchi A, Staudacher C, Bonifacio E, Battaglia M: Expansion of Th17 cells and functional defects in T regulatory cells are key features of the pancreatic lymph nodes in patients with type 1 diabetes. Diabetes 2011;60:29032913.

52 Marwaha AK, Leung NJ, McMurchy AN, Levings MK: TH17 Cells in Autoimmunity and Immunodeficiency: Protective or Pathogenic? Front Immunol 2012;3:129.

53 Emamaullee JA, Davis J, Merani S, Toso C, Elliott JF, Thiesen A, Shapiro AMJ: Inhibition of Th17 Cells Regulates Autoimmune Diabetes in NOD Mice. Diabetes 2009;58:1302-1311.

54 Bonjardim CA, Ferreira PCP, Kroon EG: Interferons: Signaling, antiviral and viral evasion. Immunol Lett 2009;122:1-11.

55 Re F, Strominger JL: Toll-like Receptor 2 (TLR2) and TLR4 Differentially Activate Human Dendritic Cells. J Biol Chem 2001;276:37692-37699.

56 Coffman RL: Origins of the T(H)1-T(H)2 model: a personal perspective. Nat Immunol 2006;7:539-541.

57 Stockinger B, Veldhoen M: Differentiation and function of Th17 T cells. Curr Opin Immunol 2007;19:281286.

58 Kim GT, Cho ML, Park YE, Yoo WH, Kim JH, Oh HJ, Kim DS, Baek SH, Lee SH, Lee JH, Kim HY, Kim SI: Expression of TLR2, TLR4, and TLR9 in dermatomyositis and polymyositis. Clin Rheumatol 2010;29:273279.

59 Krieg AM: CpG motifs in bacterial DNA and their immune effects. Annu Rev Immunol 2002;20:709-760.

60 Reis e Sousa C, Hieny S, Scharton-Kersten T, Jankovic D, Charest H, Germain RN, Sher A: In vivo microbial stimulation induces rapid CD40 ligand-independent production of interleukin 12 by dendritic cells and their redistribution to T cell areas. J Exp Med 1997;186:1819-1829.

61 Trinchieri G: Interleukin-12 and the regulation of innate resistance and adaptive immunity. Nat Rev Immunol 2003;3:133-146.

62 Agrawal S, Agrawal A, Doughty B, Gerwitz A, Blenis J, Van Dyke T, Pulendran B: Cutting Edge: Different TollLike Receptor Agonists Instruct Dendritic Cells to Induce Distinct Th Responses via Differential Modulation of Extracellular Signal-Regulated Kinase-Mitogen-Activated Protein Kinase and c-Fos. J Immunol 2003;171:4984-4989.

63 Dillon S, Agrawal A, Van Dyke T, Landreth G, McCauley L, Koh A, Maliszewski C, Akira S, Pulendran B: A TollLike Receptor 2 Ligand Stimulates Th2 Responses In Vivo, via Induction of Extracellular Signal-Regulated Kinase Mitogen-Activated Protein Kinase and c-Fos in Dendritic Cells. J Immunol 2004;172:4733-4743.

64 Redecke V, Hacker H, Datta SK, Fermin A, Pitha PM, Broide DH, Raz E: Cutting Edge: Activation of TollLike Receptor 2 Induces a Th2 Immune Response and Promotes Experimental Asthma. J Immunol 2004;172:2739-2743.

65 Abdollahi-Roodsaz S, Joosten LA, Koenders MI, Devesa I, Roelofs MF, Radstake TR, Heuvelmans-Jacobs M, Akira S, Nicklin MJ, Ribeiro-Dias F, van den Berg WB: Stimulation of TLR2 and TLR4 differentially skews the balance of T cells in a mouse model of arthritis. J Clin Invest 2008;118:205-216.

66 Moss RB, Moll T, El-Kalay M, Kohne C, Soo Hoo W, Encinas J, Carlo DJ: Th1/Th2 cells in inflammatory disease states: therapeutic implications. Expert Opin Biol Ther 2004;4:1887-1896. 